\title{
Two-Color Allele-Specific Polymerase Chain Reaction (PCR-SSP) Assay of the Leptin Receptor Gene (Leprob) for Genotyping Mouse Diabetes Mutation
}

\author{
Hiroshi SUEMIZU, Yasuyuki OHNISHI, \\ Chika MARUYAMA, and Norikazu TAMAOKI
}

Central Institute for Experimental Animals, 1430 Nogawa, Miyamae-ku, Kawasaki-shi 216-0001, Japan

\begin{abstract}
An allele specific polymerase chain reaction (PCR-SSP) assay for genotyping the mouse leptin receptor (Leprdb) mutation and its wild type (Lepr+) gene was developed using two different fluorescent dye-labeled primers. First, we determined the Leprdb and Lepr+ allele by PCR-SSP assay with usual dye-unlabeled primers. However this method requires two separate $P C R$ reactions because the amplified products specific for each allele are almost the same size. We further developed a simple and reliable two-color PCR-SSP method that uses a color complementation strategy to distinguish the Leprab and Lepr+ alleles. Leprab/Leprab, Leprdb/Lepr ${ }^{+}$and Lepr+/Lepr+ of mice (5 each) were clearly genotyped by the two-color PCRSSP. We also performed PCR-direct sequencing for the same samples and confirmed the accuracy of this method. This method makes it possible to reduce the number of PCR reactions because both alleles are amplified in the same reaction mixture.
\end{abstract}

Key words: color complementation strategy, $d b / d b$ mice, PCR-SSP

An autosomal recessive mutation in mouse diabetes $(d b)$ was first detected in progeny of the C57BL/KsJ strain at the Jackson Laboratory [7] and mapped to the middle of chromosome 4. Several reports showed that the $d b$ gene encodes leptin receptor (Lepr), and the $d b$ mutation which is a $\mathrm{G}$ to $\mathrm{T}$ transversion in the genomic leptin receptor sequence $\left(\right.$ Lepr $\left.^{d b}\right)$ generates a new splice donor site that converts the 106 nucleotides region to a novel exon retained in the leptin receptor transcript [2, $3,8]$. Both female and male mice homozygous for $L e p r^{d b}$ are sterile, and animals heterozygous for Leprdb have to be used for maintenance of the mutant stocks. To facilitate identification of heterozygotes for breed- ing, Coleman and Hummel developed mutant animals incorporating a closely linked mutant gene, misty $(m)$, into the stocks carrying the Lepr ${ }^{d b}$ mutation [4]. In these animals, mice with misty coat color are likely to bear the $\mathrm{Lepr}^{+} \mathrm{m} / \mathrm{Lepr}^{+} \mathrm{m}$ genotype and non-misty lean black animals are likely to bear the epr $^{d b}+/$ Lepr $^{+} m$ genotype. However, mice heterozygous for Lepr selected by the non-misty phenotype for further breeding might carry recombinant chromosomes between the $m$ locus and the Lepr locus, and to detect the recombination, we have to test with backcrossing. Furthermore, an assumption underlying the use of the $m$ gene as the marker for Lepr ${ }^{d b}$ genotype is that the $m$ gene has no 


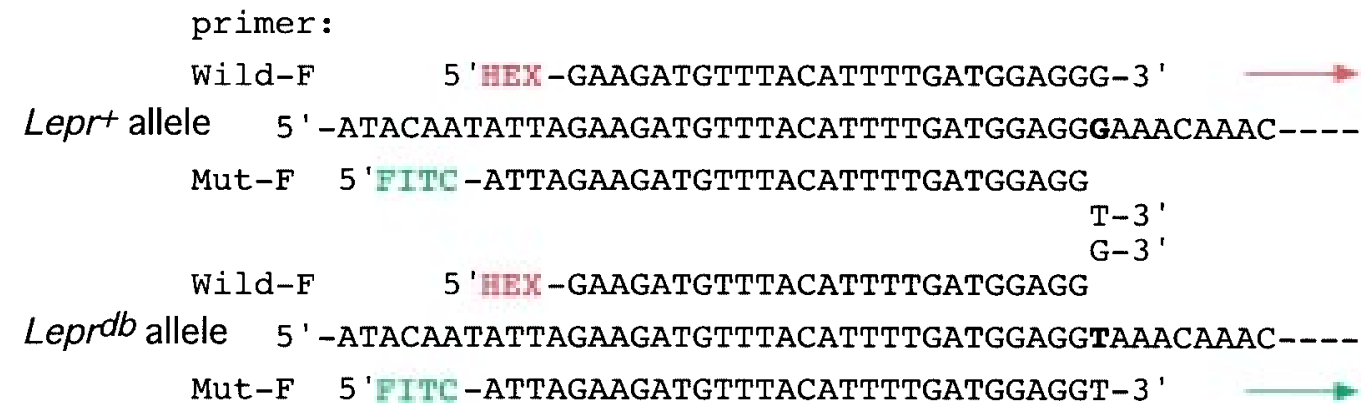

Lepr+ allele ----GTGTATATTTTGTgGCCACAATgTAGgTTTGATGTAGTTCAGTT-3 ' Leprdb allele ----GTGTATATTTTGTGGCCACAATGTAGGTTTGATGTAGTTCAGTT-3' COMR1 $3^{\prime}$-CGGTGTTACATCCAAACTACATCAAG-5

Fig. 1. Nucleotide sequence of the wild type Lepr ${ }^{+}$and mutant Lepr $^{d b}$ allele and primer sequences developing for the PCR-SSP assay. The forward primer Wild-F or Mut-F and ComR1 reverse primer were used for the PCR-SSP assay (2-tube method). Wild-F primer labeled at the 5'-end with HEX plus, Mut-F primer labeled at the 5'-end with FITC and ComR1 reverse primer were used for the two-color PCR-SSP assay. Arrow indicates a possible polymerizing reaction by Taq polymerase. The expected sizes of PCR products are $130 \mathrm{bp}$ with Wild-F and $134 \mathrm{bp}$ with Mut-F.

independent effects on phenotypes of Lepr ${ }^{d b}$. Recently, Truett and others reported that the misty gene affected growth traits including body weight, body length, and adipose mass $[10,11]$. Therefore, linkage with the misty gene for genotyping Lepr may not be desirable depending on the experimental purpose, and to solve this problem, a direct assay for genotyping Lepr is required.

We have developed a quick, easy polymerase chain reaction (PCR) based color complementation assay that detects the Lepr ${ }^{d b}$ mutation in mouse DNA. It is based on the simultaneous amplification of two DNA segments with fluorescent dye-labeled oligonucleotide primers and visualization of the resulting amplified color by UV light irradiation.

Three genotypes of mice (Lepr $r^{d b} /$ Lepr $^{d b}$, Lepr $^{d b} /$ Lepr $^{+}$ and $\mathrm{Lepr}^{+} / \mathrm{Lepr}^{+}$) with C57BL/KsJ background were obtained from CLEA Japan Inc. (Tokyo). Tail chips of the mice were cut and digested with proteinase $\mathrm{K}$ by ordinary methods [9]. Genomic DNA was extracted using GeneExtractor TA-100 (Takara Inc., Tokyo) according to the manufacturer's instructions.

Figure 1 shows the sequence of the wild type Lepr ${ }^{+}$ and mutant Lepr $^{d b}$ allele, and primer sequences developed for the PCR-SSP assay. The forward primer
Wild-F and Mut-F were labeled at the 5'-end with HEX and FITC, respectively, when used for the two-color PCR-SSP assay. The ComR1 primer functioned as a reverse primer for amplification of wild type Lepr $^{+}$and mutant $\operatorname{Lepr}^{d b}$ allele. Figure 2 shows 6\% polyacrylamide gel stained with ethidium bromide. Samples No. 1-4 represent wild type control $\left(\mathrm{Lepr}^{+} / \mathrm{Lepr}^{+}\right)$, samples No. 5-8 heterozygous $\left(\right.$ Leprdb $^{d} /$ Lepr $\left.^{+}\right)$, and samples No. 9-12 homozygous mutant ( Lepr $^{d b} /$ Lepr $\left.^{d b}\right)$. The internal GAPDH control was seen together with the wild type allele in the primer set w (samples No. 1 to 4, Lepr ${ }^{+} /$ Lepr $^{+}$; No. 5 to 8, Leprdb/Lepr ${ }^{+}$), and together with the mutant allele in the primer set $\mathrm{m}$ of the lane (samples No. 5 to 8; No. 9 to 12, Lepr ${ }^{d b} /$ Lepr $^{d b}$ ). Figure 3 shows a 4\% Nusive GTG 3:1 agarose gel (BioWhittaker Molecular Aplications, ME) scanned with two-color detection. The gel was scanned with 488-nm and 514$\mathrm{nm}$ excitation beams using a FluorImager 595 (Molecular Dynamics, Inc., CA) with a two-channel scan mode. FITC and HEX fluorescent emissions were separated using 530DF30 and 570DF30 band-pass filters. The ImageQuaNT Fluorochrome Separation utility (Molecular Dynamics, Inc.) removed cross-talk caused by overlapping dye spectra. For image display, the red-green palette was chosen so that the wildtype $\mathrm{Lepr}^{+}$ 


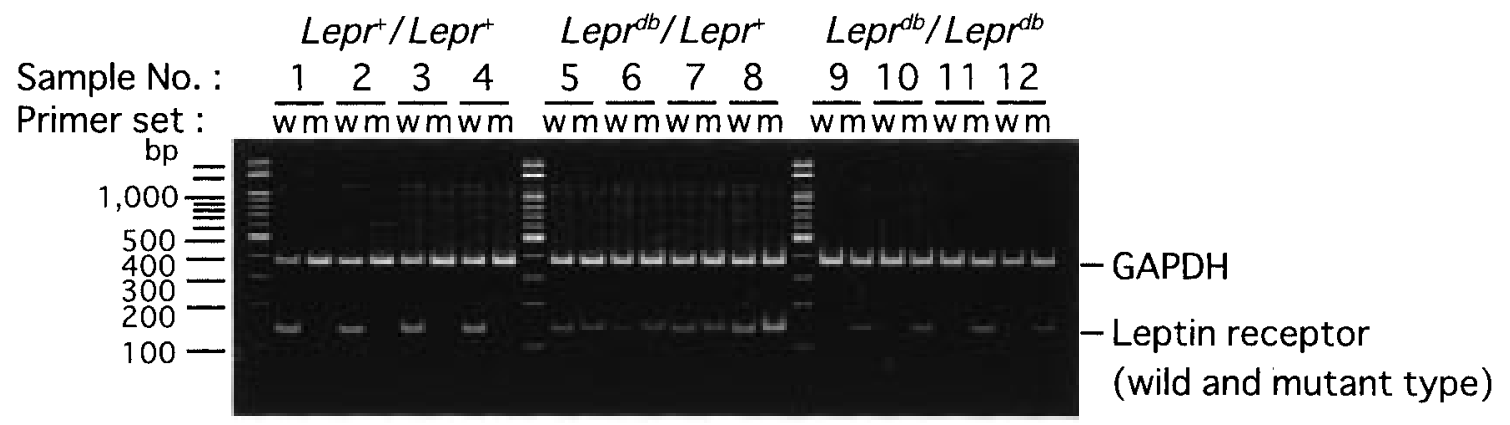

Fig. 2. Detection of the leptin receptor mutation by PCR-SSP (2-tube method). Each sample was investigated with two PCR amplifications, one amplifying the wild type (WildF sense/ComR1 antisense; primer set w) and the other amplifying the leptin receptor point mutation (MutF sense/ComR1 antisense; primer set $\mathrm{m}$ ). Each PCR primer mix included a primer pair (G3PGENEF: 5'-TCAGGTACCCCAGATGACGG-3', G3PGENER: 5' TACAGGATGCATTGCTGAAACG-3') that amplified a fragment of the mouse glyceraldehyde 3-phosphate dehydrogenase (GAPDH) gene as an internal positive amplification control, resulting in a 377 bp PCR fragment. One hundred nanograms of genomic DNA was suspended in a total volume of $20 \mu \mathrm{l}$ of PCR buffer, containing $10 \mathrm{mM}$ Tris- $\mathrm{HCl}$ ( $\mathrm{pH} 8.3$ ), $50 \mathrm{mM} \mathrm{KCl}, 1.5 \mathrm{mM} \mathrm{MgCl}_{2}, 1 \mu \mathrm{M}$ of each primer, $0.2 \mu \mathrm{M}$ dNTPs, and 0.5 unit of Taq DNA polymerase (TaKaRa Inc., Tokyo). Thermal cycling conditions were as follows: $94^{\circ} \mathrm{C}, 2 \mathrm{~min}$ followed by 35 cycles of $94^{\circ} \mathrm{C}, 30 \mathrm{sec} ; 62^{\circ} \mathrm{C}, 30 \mathrm{sec} ; 72^{\circ} \mathrm{C}, 20 \mathrm{sec} ; 72^{\circ} \mathrm{C}, 1 \mathrm{~min}$. For visualization purposes, $5 \mu \mathrm{l}$ of the amplification product was subjected to electrophoresis on a $6 \%$ polyacrylamide gel/0.5X TAE and then stained with ethidium bromide $(0.25 \mu \mathrm{g} / \mathrm{ml})$. The PCR products with primer set w were seen in samples No. 1to 4 (wild type control, Lepr $^{+} /$eepr $^{+}$) and samples No. 5 to 8 (heterozygous, Lepr ${ }^{d b} /$ Lepr $^{+}$). The PCR products with primer set m were seen in samples No. 5 to 8 (heterozygous) and samples No. 9 to12 (homozygous mutant; Lepr db/Leprdb).

allele appears in red and mutant Lepr $^{d b}$ allele appears in green. The lane of samples No. $1-5$ is a PCR product amplified from homozygous normal samples ( Lepr $^{+} /$ Lepr $^{+}$) and shows fluorescence only in the red image (Fig. 3, channel 1). The lane of samples No. 11-15 is an amplified product from a homozygous sample $\left(\right.$ Lepr $^{d b} /$ Lepr $\left.^{d b}\right)$ and shows fluorescence only in the green image (Fig. 3, channel 2). The lane of samples No. 610 is a PCR product amplified from a heterozygous sample $\left(\right.$ Lepr $^{d b} /$ Lepr $\left.^{+}\right)$and shows fluorescence in both the red and green images (Fig. 3, channels 1 and 2). Therefore, these overlapping red and green images appear yellow in color (Fig. 3, overlay). The gel was further stained with ethidium bromide, and PCR products of the expected size were observed (data not shown).

To provide evidence that the two-color PCR-SSP assay correctly determines the genotype, we performed a sequencing analysis of the PCR-amplified fragment directly. Figure 4 represents a typical sequencing pattern for three genotypes, eepr $^{+} /$Lepr $^{+}$(left), Lepr ${ }^{d b} /$ Lepr $^{+}$ (center), and Lepr ${ }^{d b} / L_{e p r}{ }^{d b}$ (right) determined by our method. We tested 15 DNA samples (five each of the three genotypes), and all genotypes determined by the two-color PCR-SSP assay were consistent with the results of DNA sequencing analysis at the Lepr gene mutation site $[2,3,8]$. These results suggest that the two-color PCR-SSP assay can accurately determine the genotypes at the Leprdb mutation site.

Since single base substitution in the leptin receptor gene has been identified as the molecular basis of the diabetic $(d b)$ mutation $[2,3,8]$, misty can be replaced as a marker for the Lepr ${ }^{d b}$ genotype when assays that detect the single base substitution are developed. The PCR has revolutionized the detection and characterization of specific DNA sequence changes. Several PCR-based methods for detecting single base substitution have been developed: e.g. restriction fragment length polymorphism (PCR-RFLP) and single-strand conformation polymorphism (PCR-SSCP) analysis or sequencing (PCR-direct sequencing). The approach for the determination of the genotype at the Lepr ${ }^{d b}$ mutation by PCR-RFLP using modified primers has been described by Horvat and Bunger [6]. With this assay, it is possible to identify the Lepr ${ }^{d b}$ genotypes in only a one-tube PCR reaction. However, this assay requires a post-amplification procedure, enzymatic reaction with restriction endonuclease, to identify the mutation. In 


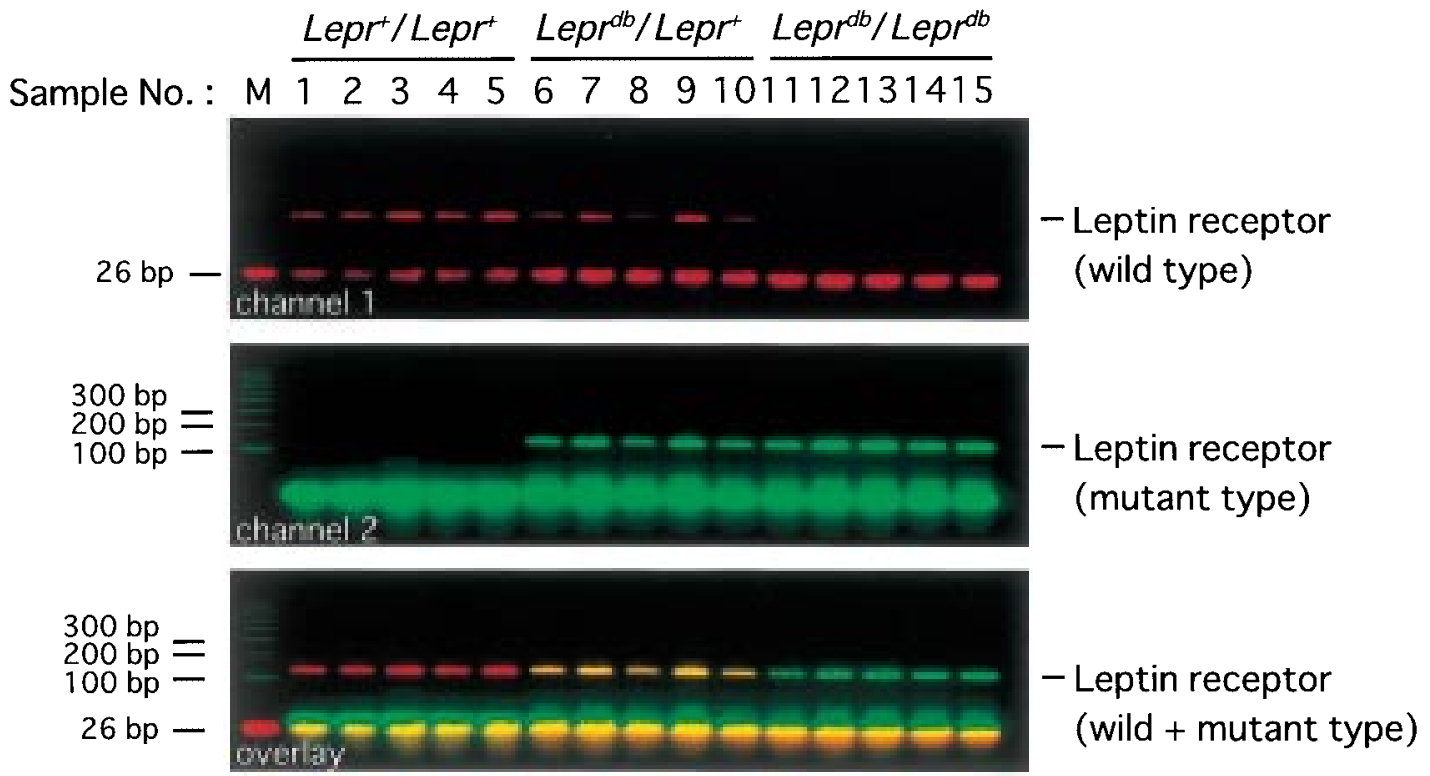

Fig. 3. Detection of the leptin receptor mutation by two-color PCR-SSP. Each sample was investigated with only one PCR amplification, one amplifying the wild type (5'HEX-Wild-F sense/ComR1 antisense) with a red image and the other amplifying the leptin receptor point mutation (5'FITC-Mut-F sense/ComR1 antisense) with a green image. Two hundred nanograms of genomic DNA was suspended in a total volume of $20 \mu l$ of PCR buffer, containing $10 \mathrm{mM}$ Tris- $\mathrm{HCl}(\mathrm{pH} 8.3), 50 \mathrm{mM} \mathrm{KCl}, 1.5 \mathrm{mM} \mathrm{MgCl}_{2}, 0.1 \mu \mathrm{M}$ of each fluorescent dye labeled specific forward primer, $0.2 \mu \mathrm{M}$ reverse primer, $0.2 \mathrm{mM} \mathrm{dNTPs}$, and 0.5 unit of Taq DNA polymerase (TaKaRa Inc., Tokyo). The thermal cycle protocols are the same as described above. The amplification product $(10 \mu l)$ was subjected to electrophoresis on a $4 \%$ Nusive 3:1 agarose gel/0.5X TAE and then the gels were scanned with a FluorImager 595 (Molecular Dynamics) using a 530DF30 bandpass filter to record FITC emissions $(1 \mathrm{em} \max =520 \mathrm{~nm})$ and a 570DF30 bandpass filter to record HEX emissions $(1 \mathrm{em} \max =560 \mathrm{~nm})$. We then processed the image using a FITC-labeled $100 \mathrm{bp}$ DNA ladder marker and HEX-labeled 26 bp oligonucleotide as fluorochrome standards. The ImageQuaNT Fluorochrome Separation utility allowed us to correct for the overlapping spectra of the fluorescent dyes. For image display, the red-green palette was chosen so that the homozygous Lepr $^{+} /$Lepr $^{+}$normal sample appeared in red (channel 1) and the homozygous Lepr ${ }^{d b} /$ Lepr $^{d b}$ mutant sample appeared in green (channel 2). A band that appears both red and green indicates a heterozygous Lepr $^{\text {db }} /$ Lepr $^{+}$sample (overlay).
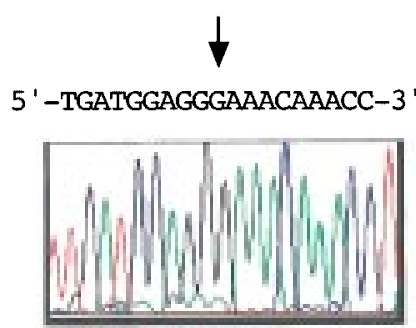

Lepr $r^{+} /$Lepr $^{+}$
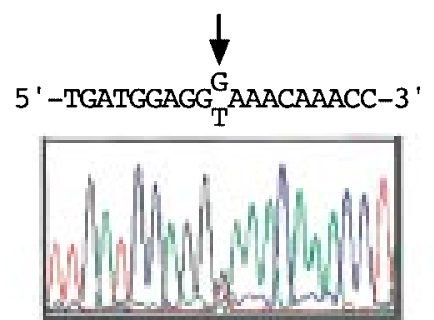

Lepr ${ }^{d b} /$ Lepr $^{+}$
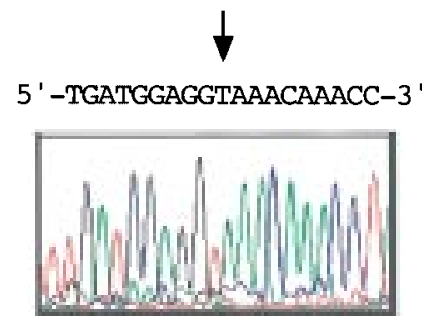

$\operatorname{Lepr}^{d b} / \operatorname{Lepr}^{d b}$

Fig. 4. Direct sequencing of the leptin receptor gene mutation site at lepr locus. The junction region between intron 17 and exon 18 containing the mutation site was amplified with PCR using forward (db-Seq1: 5'CAAGTGAGGGCGAGCAGTCCC-3') and reverse (db-Seq2: 5'-CCCTGAAAATCAAGCATATGTCC3') primers. The PCR products were purified using the UltraClean PCR Clean-up DNA purification kit (MO Bio). The purified PCR product was directly sequenced with both end primers. DNA sequencing was performed on the ABI PRISM 310 Genetic analyzer using ABI PRISM BigDye terminator cycle sequencing ready reaction kits (ABI). Arrow indicates the $\mathrm{G}$ to $\mathrm{T}$ transversion mutation site in the genomic leptin receptor sequence. 
the first experiment, we employed an allele-specific PCR (PCR-SSP) as a screening method for Lepr ${ }^{d b}$. The presence or absence of a specific PCR fragment is sufficient for allele assignment. No further postamplification procedures, such as enzymatic reaction in RFLP or sequencing, are required for identification of the point mutation. A disadvantage of this assay is that each allele specific PCR process is performed in independent tubes; therefore, this PCR-SSP method requires a larger number of reactions compared with the PCRRFLP method. To save costs and time, we further developed a simple and reliable two-color PCR-SSP method that uses a color complementation strategy [1] to detect the Lepr ${ }^{d b}$ mutation. The use of this color complementation strategy has been described by Fortina et al. [5] for the fluorescence-based, multiplex allelespecific PCR assay of the cystic fibrosis transmembrane conductance regulator (CFTR) mutation DF508CF. The use of two different color primers in the PCR reduces the number of reactions by half because both alleles are amplified in the same reaction mixture. The two-color PCR-SSP method also decreases the risk of erroneous results caused by reaction failures in separate allelespecific amplification reactions. In this way, one allele-specific primer serves as a PCR reaction control for the other allele-specific primer. The two-color PCRSSP approach also provides cost-effective testing for large-scale screening programs. The obese phenotype in the mouse is not remarkable in the early stages of life, and the direct genotyping assay developed in this study would be helpful for determining genotypes at any age in mice.

We thank Katsura Ishiwari for excellent technical assistance.

\section{References}

1. Chehab, F.F. and Kan, Y.W. 1989. Proc. Natl. Acad. Sci. U.S.A. 86: 9178-9182.

2. Chen, H., Charlat, O., Tartaglia, L.A., Woolf, E.A., Weng, X., Ellis, S.J., Lakey, N.D., Culpepper, J., Moore, K.J., Breitbart, R.E., Duyk, G.M., Tepper, R.I., and Morgenstern, J.P. 1996. Cell 84: 491-495.

3. Chua, S.C., Chung, W.K., Wu-Peng, X.S., Zhang, Y., Liu, S.M., Tartaglia, L., and Leibel, R.L. 1996. Science 271: 994-996.

4. Coleman, D.L. and Hummel, K.P. 1975. Isr. J. Med. Sci. 11: 708-713.

5. Fortina, P., Conant, R., Parrella, T., Rappaport, E., Scanlin, T., Schwartz, E., Robertson, J.M., and Surrey, S. 1992. Mol. Cell. Probes 6: 353-356.

6. Horvat, S. and Bunger, L. 1999. Lab. Anim. 33: 380-384.

7. Hummel, K.P., Dickie, M.M., and Coleman, D.L. 1966. Science 153: 1127-1128.

8. Lee, G.H., Proenca, R., Montez, J.M., Carroll, K.M., Darvishzadeh, J.G., Lee, J.I., and Friedman, J.M. 1996. Nature 379: 632-635.

9. Maniatis, T., Fritsch, E.F., and Sambrook, J. 1982. In: Molecular Cloning: a laboratory manual. pp. 9.14-9.19. 2nd ed., Cold Spring Harbor Press.

10. Sviderskaya, E.V., Novak, E.K., Swank, R.T., and Benntt, D.C. 1998. Genetics 148: 381-390.

11. Truett, G.E., Tempelman, R.J., Walker, J.A., and Wilson, J.K. 1998. Am. J. Physiol. 275: R29-R32. 